\title{
Cervical Spondylotic Myelopathy: Can MR Spectroscopy Be Helpful?
}

\author{
MONA A. EL-HARIRI, M.D. and NESREEN MOHEY, M.D. \\ The Department of Radio-Diagnosis, Faculty of Medicine, Zagazig University, Zagazig, Egypt
}

\begin{abstract}
Background: Spinal cord myelopathy can happen due to cord compression in variable situations. Understanding biochemical and metabolic changes in myelopathy are needed to expect treatment outcomes. The non-invasive technique of $1 \mathrm{H}-\mathrm{MRS}$ can provide data about chemical microenvironment related to tissue metabolic changes by measuring of $\mathrm{N}$-acetylaspartate (NAA), choline (Cho), and creatine (Cr) [1-8]
\end{abstract}

Aim of Study: The aim of current study is to evaluate the diagnostic value of $1 \mathrm{H}-\mathrm{MRS}$ in the assessment of biochemical changes in cervical spondylotic myelopathy.

Subjects and Methods: 26 subjects with cervical myelopathy and 12 volunteers who were age-matched with no neurological problems were considered as control group. MR spectroscopy was done and analysis of MRS to detect NAA (2.0ppm), Cho (3.25ppm), Cr (3.03ppm) and Lactate (Lac) (1.32ppm). Recording of NAA/Cr as well as $\mathrm{Cho/Cr}$ were done.

Results: Detection of peak of lactate was possible in 10 patients; however no lactate peak was noted in the members of control group.

The NAA/Cr ratio was recorded and comparison was done between patient and control group and showed significant difference as the mean NAA/Cr in control subjects equaled $1.87 \pm 0.05$ versus $1.33 \pm 0.057$ for patient group $(p<0.0001)$ Figs. (2-6).

Furthermore mean NAA/Cr ratio in subjects with lactate peak was lower than that in patients without such peak $(1.268 \pm 0.028$ versus $1.365 \pm 0.034)$ with significant difference $(p<0.0001)$.

There was no significant difference between the mean $\mathrm{Cho} / \mathrm{Cr}$ ratio in patient group and control group (mean= $0.783 \pm 0.065$ versus $0.764 \pm 0.049, p=0.38$ ).

Also the mean ratio of $\mathrm{Cho} / \mathrm{Cr}$ of lactate peak patients was not significantly different from those without lactate $(0.79 \pm 0.074$ versus $0.77 \pm 0.061, p=0.44)$.

Conclusion: MRS can provide good data about the metabolic changes in patients with Cervical Spondylotic Myelopathy (CSM).

Key Words: MRS - Myelopathy - Cervical - MRI - Spondylosis.

Correspondence to: Dr. Mona A. El-Hariri, The Department of Radio-Diagnosis, Faculty of Medicine, Zagazig University, Zagazig, Egypt

\section{Introduction}

NEUROLOGICAL deficits of spinal cord (myelopathy) can happen due to cord compression in variable situations such as congenital stenosis of spinal canal, osteophyte or disc prolapse compression, however cervical spondylotic myelopathy on top of reasons of malfunction of spinal cord in old population [1-5] . Magnetic Resonance Imaging (MRI) can supply anatomical information in cases of spondylotic myelopathy, however understanding the biochemical and metabolic changes is still needed to expect treatment outcomes [6-9]. This can be achieved by using of proton MR spectroscopy ( $\left.{ }^{1} \mathrm{H}-\mathrm{MRS}\right)$. The non-invasive technique of ${ }^{1} \mathrm{H}-\mathrm{MRS}$ is a tool that can provide data about chemical microenvironment related to tissue metabolic changes by measuring of N-Acetyl-Aspartate (NAA), choline (Cho), and creatine(Cr) [8-14].

MRS evaluation of the spinal cord was studied in earlier reports [11-18] and showed useful additional information that improved the clinical management of cord disorder as multiple sclerosis and tumors of cord.

The aim of current work is to assess the diagnostic value of ${ }^{1} \mathrm{H}-\mathrm{MRS}$ in the evaluation of metabolic changes in spondylotic myelopathy of cervical cord.

\section{Material and Methods}

This study included patients with cervical myelopathy referred from Neurology and Internal Medicine Outpatient Clinics to Radiology Department for MR imaging in Zagazig University Hospital in the period of (January 2017 to December 2017).

This study was approved by our Institute's Research Ethics Committee and informed consents were obtained from all subjects prior to enrollment. 
All procedures involving human participants were in accordance with the ethical standards of the institutional and National Research Committee and with the 1964 Helsinki declaration and its later amendments or comparable ethical standards.

This study included 31 patients with cervical myelopathy diagnosed on clinical and radiographic bases. Five of those patient were excluded due to previous surgery for cervical disc $(n=3)$, MRIincompatible implants $(\mathrm{n}=1)$ and claustrophobia $(n=1)$. The rest of patients (patient group, $n=26)$ were exposed to the MRI study examination.

Patients were 16 males and 10 females. The mean age was $52 \pm 10.5$ years (ranging from 48-62 years).

On the other hand 12 volunteers who were agematched with no neurological problems were considered as control group.

\section{MR protocol:}

1.5-T MR (Philips, Achieva, Netherland B.V.) was used. The patient was placed supine and surface neck coil was applied (circular polarization). Instruction was given not to move during the examination. Axial, sagittal and coronal scout was done first then other sequences were completed include:

- Conventional MRI: T1-weighted images sagittal and axial (repetition time (TR) 4500-600, echotime (TE) 8-9msec.). T2-WI fast spin-echo axial and sagittal images (TR/TE $=3000 / 100 \mathrm{msec}$.). Slice thickness of $3-4 \mathrm{~mm}$ and inter-slice gap= $1 \mathrm{~mm}$. Field of View (FOV): 250mm. Flip angle: 90 degrees.

-MRS: All patients and control groups underwent MRS (single voxel spectra) using point resolved spectroscopy (PRESS) (spin-echo sequence (TR/TE $=2000 / 36 \mathrm{msec}$. Width of spectrum $=1000$ $\mathrm{Hz}$, signal acquisition 64, points number: 512 . Scan time average about $4.46 \mathrm{~min}$. Water was suppressed using a three pulse chemical shift selective (CHESS), Very Selective Suppression (VSS) pulse saturation bands were applied to the Volume of Interest (VOI) to reduced fat contamination. Dedicated software had automatically processed the data. Application pulse oximeter triggering during MRS was used to diminish the CSF and spinal cord motion artefact.

The voxel positioning was along longitudinal cord axis avoiding inclusion of surrounding tissues and CSF. C2 and C2-3 level was chosen to diminish the artifacts and for better signal to noise ratio that is influenced by the narrow cross section of cord [17] Fig. (1).

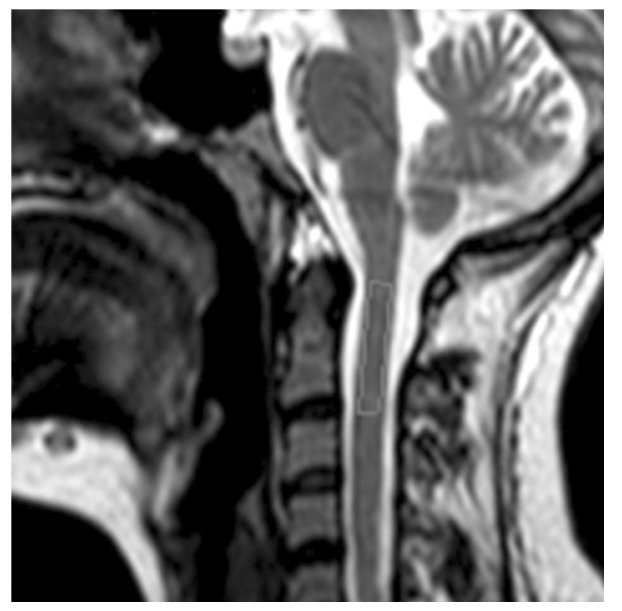

Fig. (1): Voxel box placement opposite C2 \& C2-3 levels.

\section{Image interpretation:}

Routine T1 and T2 WI were evaluated for any pathology.

For MRS, voxel was located at the level of $\mathrm{C} 2$ and $\mathrm{C} 2-3$. It measured (transverse, anteroposterior and cranio-caudal: $10 \times 8 \times 15-20 \mathrm{~mm}$ respectively).

Voxel was placed on the cord with exclusion of and other surrounding tissues. Analysis of MRS to detect NAA (2.0ppm), Cho (3.25ppm), Cr (3.03 $\mathrm{ppm})$ and Lactate (Lac) (1.32ppm) as well as Cho/ $\mathrm{Cr}$ and NAA/Cr were done.

\section{Statistical analysis:}

Statistical analysis was done by SPSS version 17. Calculation of the mean and SD (standard deviation) of NAA/Cho and Cho/Cr was done for each group (patients and controls), $t$-test was applied to compare results of both groups with $p$ value $<0.05$ assumed to be significant.

\section{Results}

Detection of lactate peak was possible in 10 patients, however no lactate peak was noted in the members of control group Figs. (2-6).

The NAA/Cr ratio was recorded and comparison was done between patient and control group and showed significant difference as the mean NAA/Cr in control group was $1.87 \pm 0.05$ versus $1.33 \pm 0.057$ for patient group $(p<0.0001)$.

Furthermore comparison of mean NAA/Cr ratio in subjects with lactate peak was lower than in patients without such peak $(1.268 \pm 0.028$ versus $1.365 \pm 0.034)$ this difference was significant; $p<$ $0.0001)$. 


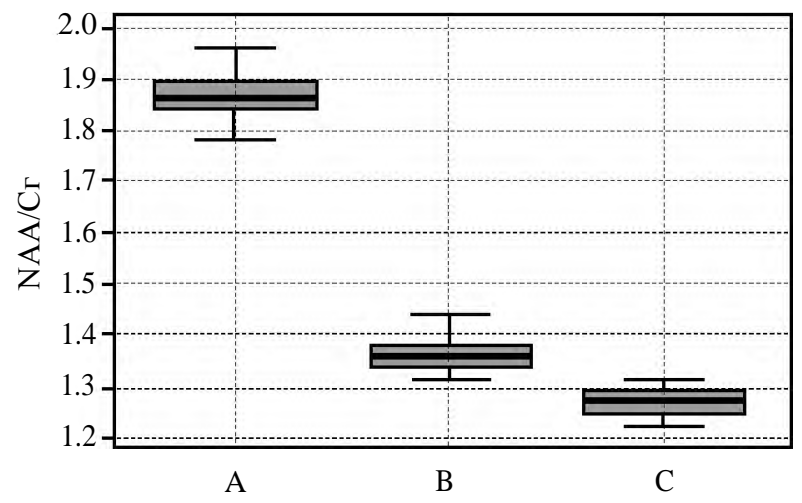

Fig. (2): Box plots shows NAA/Cr ratio in the study (A): Control, (B): Patients without Lac peak and (C): Patients with Lac peak.

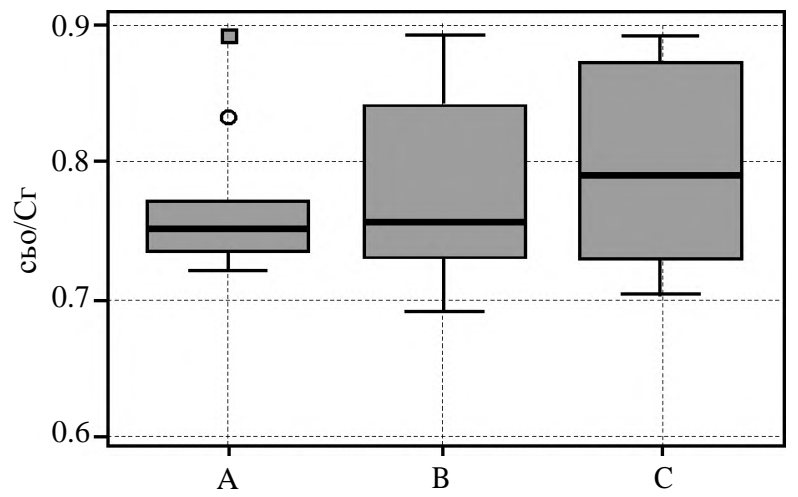

Fig. (3): Box plots shows $\mathrm{Cho} / \mathrm{Cr}$ ratio in the study (A): control, (B): Patients without Lac peak and (C): Patients with Lac peak.
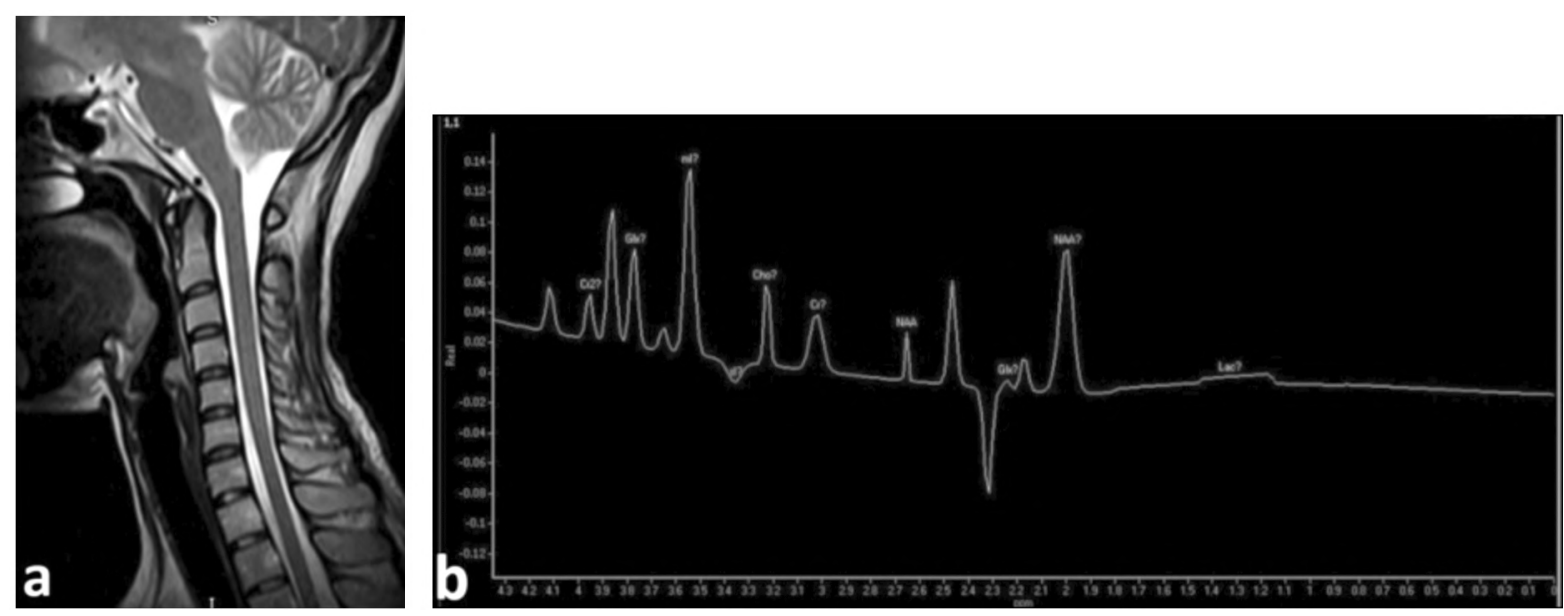

Fig. (4): Control subject (neurologically free) (A) Sagittal T2 WI MR of cervical spine (B) MRS showing normal ratio of NAA/Cr. No lactate peak seen.
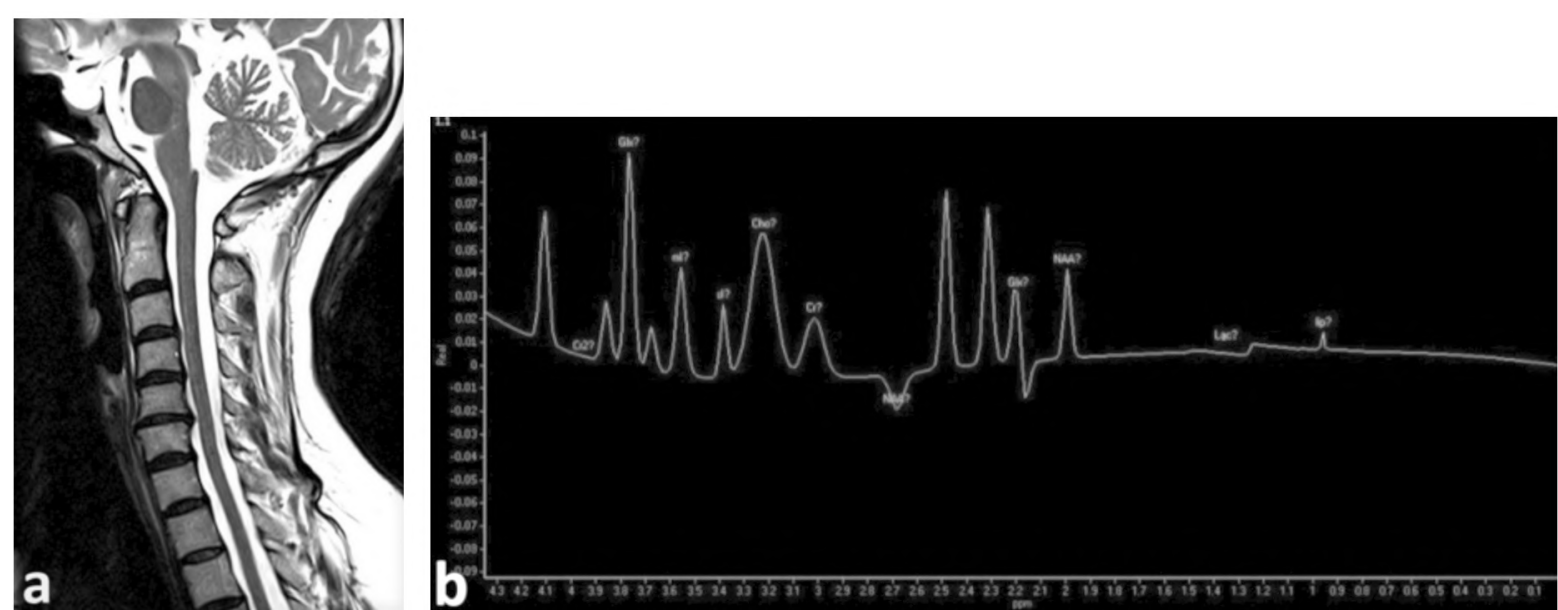

Fig. (5): CSM patient (A) Sagittal T2 WI MRI of cervical spine showing mild compression of thecal sac (B) MRS showing reduced NAA/Cr ratio. No detected lactate peak. 

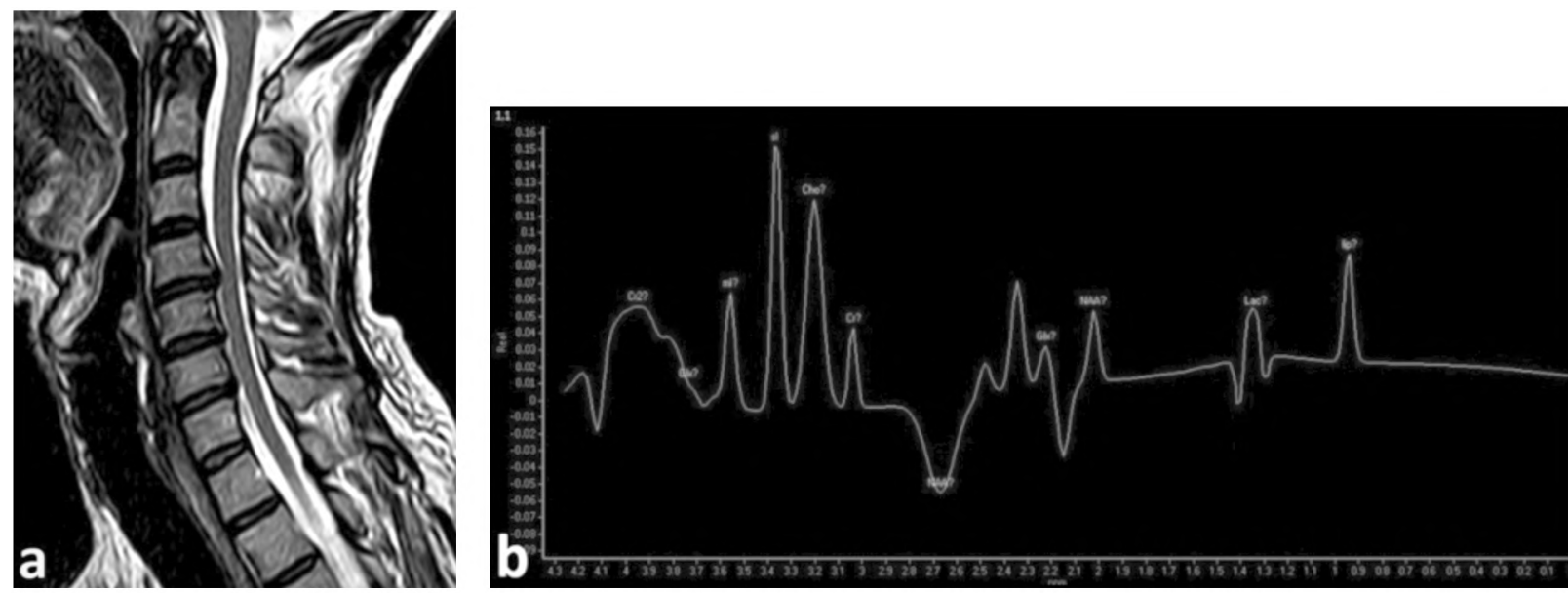

Fig. (6): Patient with CSM (A) Sagittal T2 WI MRI of cervical spine showing cord compression. (B) MRS showing reduced $\mathrm{NAA} / \mathrm{Cr}$ with lactate peak seen.

No significant difference was detected between the mean ratio of $\mathrm{Cho} / \mathrm{Cr}$ in patient group and control group (mean $=0.783 \pm 0.065$ versus $0.764 \pm$ $0.049, p=0.38)$.

Also the mean ratio of $\mathrm{Cho} / \mathrm{Cr}$ of patients with peak of lactate was not significantly different from those without lactate $(0.79 \pm 0.074$ versus $0.77 \pm$ $0.061, p=0.44)$ (Tables 1,2).

Table (1): Lactate peak occurrence in current study.

\begin{tabular}{lccc}
\hline & Patient & Control & Total \\
\hline Present & 10 & 0 & 10 \\
Absent & 16 & 12 & 28 \\
\hline Total & 26 & 12 & 38 \\
\hline
\end{tabular}

Table (2): Mean NAA/Cr and Cho/Cr ratio in current study.

\begin{tabular}{lll}
\hline & \multicolumn{1}{c}{ NAA/Cr } & \multicolumn{1}{c}{ Cho/Cr } \\
\hline Control & $1.87 \pm 0.05$ & $0.783 \pm 0.065$ \\
Patient group & $1.33 \pm 0.057$ & $0.764 \pm 0.049$ \\
Patient with Lactate peak & $1.268 \pm 0.028$ & $0.79 \pm 0.074$ \\
Patient without Lactate peak & $1.365 \pm 0.034$ & $0.77 \pm 0.061$ \\
\hline
\end{tabular}

\section{Discussion}

MRS is considered as a non-invasive modality which is able to give the metabolic and biochemical data depending on markers such as NAA, $\mathrm{Cr}$, Cho and Lac [15].

NAA is nearly present in neurons as well as axons exclusively which thus can be a measurement of the density of neurons and estimation of normal function of neurons as well as its integrity [17-20]

Cho accompanies the turnover of cell membrane so can change with alteration in the synthesis and degradation of membrane of neurons [20] .
Creatine can be and internal marker as it is relatively constant and predict global metabolic activity of the cells [10].

Lactate is present in anaerobic metabolism which can occur in inflammatory and ischemic conditions [21]

Cooke et al., [15] showed a protocol for MRS that can be optimum for the cervical cord using combination of field-maps and data from experiments and could detect metabolite concentration in cervical cord in 6 normal subjects using (PRESS) volume localization.

In preliminary study of Gomez-Anson et al., [18] for 6 normal subjects, the mean NAA/Cr ratio was estimated as $1.28 \pm 0.48$ and $\mathrm{Cho} / \mathrm{Cr}$ as 0.45 \pm 0.17 . They suggested MRS can have potenti help in cord examination.

In earlier study [17] using 3 T MRI system, MRS could show a significantly different concentration of NAA, $\mathrm{Cr}$ and Cho in spinal cord and brainstem.

Several studies was carried out to assess the MRS some spinal cord diseases, many reports stated that cervical cord NAA is diminished, $\mathrm{Cho} / \mathrm{Cr}$ is increased in multiple sclerosis cases compared to healthy subjects $[16,17,22-24]$.

In the current study peak of lactate was noted in $10 / 26$ patients however no lactate peak was noted in any control group members this can be attributed to inflammatory and ischemic conditions, this matches with earlier study [21] which detected Lac peak in $1 / 3$ of patients with CSM and also the study of Ali et al., [14] who found Lac peak among 9/24 patients with CSM), both studies did not detect lactate peak in any of control group. 
In the current work, ratio of NAA/Cr was lower in CSM (mean $=1.33 \pm 0.057$ ) in comparison to normal control (mean $=1.87 \pm 0.05$ ) this difference was significant: $p<0.0001$ ), furthermore it was lower in patient with lactate peak than those patient without lactate peak $(1.268 \pm 0.028$ versus $1.365 \pm$ $0.034, p<0.0001)$. This can be explained by the damage of axons and neurons in CSM which may not have apparent conventional MRI findings.

This agrees with a previous study [14] which also showed significantly low ratio of NAA/Cr in CSM patients (mean $=1.34 \pm 0.09)$ than controls (mean $=1.82 \pm 0.08),(p<0.0001)$ with the mean lower in patients having Lac peak than those having no Lac peak (mean $=1.31 \pm 0.10$ versus $1.36 \pm 0.09$ ). This also coincides with results of Holly et al., [16] in which they concluded a significant trend of diminished NAA/Cr CSM subjects when compared to control group (1.27 versus $1.83 ; p<0.0001)$.

In current work we did not detected any significance in difference between mean $\mathrm{Cho} / \mathrm{Cr}$ ratio in patient group compared to control group (mean $=0.783 \pm 0.065$ versus $0.764 \pm 0.049, p=0.38$ ) nor between patients with lactate peak and those without lactate $(0.79 \pm 0.074$ versus $0.77 \pm 0.061, p=0.44)$.

This matches with earlier study [14] who also could not detect any significant difference between patient and control group (mean $=0.82 \pm 0.12$ versus $0.75 \pm 0.14$ respectively), also this in line with Holly et al., [16] who also could not detect any significantly difference in $\mathrm{Cho} / \mathrm{Cr}$ ratio when compared patients and controls.

Spinal cord MRS has some difficulties, firstly the CSF motion artefacts as well as pulsatile CSF flow which cause heartbeat related cord movement. Another limitation is the challenge to make a balance between image resolution in small cervical cord cross section as well as applying a volume of interest free from other tissues contamination. Small cohort of this study is another limitation of current study; further studies with larger population may be needed.

\section{Conclusion:}

MRS can provide good data about the changes in the metabolites in cases of cervical spondylotic myelopathy.

\section{Conflict of interest:}

The authors report no conflict of interest.

\section{References}

1- NAGASHIMA H., MORIO Y., MESHITSUKA S., YAMANE K., NANJO Y. and TESHIMA R.: High-resolution nuclear magnetic resonance spectroscopic study of metabolites in the cerebrospinal fluid of patients with cervical myelopathy and lumbar radiculopathy. Eur. Spine. J., 19: 1363-8, 2010.

2- LIN A.P.: Overcoming Technical Challenges of MR Spectroscopy in Chronic Spinal Cord Injury. Radiology, 291 (1). https://doi.org/10.1148/radiol.2019190067, 2019.

3- MURONE I.: The importance of the sagittal diameters of the cervical spinal canal in relation to spondylosis and myelopathy. J. Bone. Joint. Surg. Br., 56: 30-6, 1974.

4- WONG T.M., LEUNG H.B. and WONG W.C.: Correlation between magnetic resonance imaging and radiographic measurement of cervical spine in cervical myelopathic patients. J. Orthop. Surg., 12 (2): 239-42, 2004.

5- YUKAWA Y., KATO F., YOSHIHARA H., YANASE M. and ITO K.: MR T2 image classification in cervical compression myelopathy. Spine, 32: 1675-8, 2007.

6- ALEKSANDEREK I., MCGREGOR S.M.K., STEVENS T.K., GONCALVES S., BARTHA R. and DUGGAL N.: Cervical Spondylotic Myelopathy: Metabolite Changes in the Primary Motor Cortex after Surgery. Radiology, (282): 3.817-826, 2017.

7- ALAFIFI T., KERN R. and FEHLINGS M.: Clinical and MRI predictors of outcome after surgical intervention for cervical spondylotic myelopathy. Neuroimaging, 17: 31522, 2007.

8- WONG S.H., BOGGILD M., ENEVOLDSON P. and FLETCHER N.A.: Myelopathy but normal MRI: Where next. Practical Neurology, 8 (2): 90-102, 2008.

9- SURI A., CHABBRA R.P., MEHTA V.S., GAIKWAD S. and PANDEY R.M.: Effect of intramedullary signal changes on the surgical outcome of patients with cervical spondylotic myelopathy. Spine. J., 33-45, 2003.

10- TIEHUIS A., MEER F., MALI W., PLEIZIER M., BIESSELS G., KAPPELLE J., et al.: MR spectroscopy of cerebral white matter in type 2 diabetes; no association with clinical variables and cognitive performance. Neuroradiology, 52: 155-61, 2010.

11-NAKASHIMA H., YUKAWA Y., SUDA K., YAMAGATA M., UETA T. and KATO F.: Abnormal findings on magnetic resonance images of the cervical spines in 1211 asymptomatic subjects. Spine., 40 (6): 392-8, 2015.

12- ZHANG C., DAS S.K., YANG D.J. and YANG H.F.L.: Application of magnetic resonance imaging in cervical spondylotic myelopathy. World Journal of Radiology, (4): 826-32, 2014.

13- SEIDENWURM D.J.: Myelopathy. AJNR, 29 (5): 1032 4, 2008.

14- TAMER T.A. and BADAWY A.E: Feasibility of 1H-MR Spectroscopy in evaluation of cervical spondylotic myelopathy. EJRNM, 44: 93-9, 2013.

15- COOKE F.J., BLAMIRE A.M., MANNERS D.N., STYLES P. and RAJAGOPALAN B.: Quantitative proton magnetic resonance spectroscopy of the cervical spinal cord. Magn. Reson. Med., 51: 1122-8, 2004. 
16- HOLLY L.T., FREITAS B., ARTHUR D. and SALAMON N.: Proton magnetic resonance spectroscopy to evaluate spinal cord axonal injury in cervical spondylotic myelopathy, laboratory investigation. J. Neurosurg. Spine, 10 194-200, 2009.

17- MARLIANI A.F., CLEMENTI V., ALBINI-RICCIOLI L., AGAIT R. and LEONARDI M.: Quantitative proton magnetic resonance spectroscopy of the human cervical spinal cord at 3 Tesla. Magn. Reson. Med., 57: 160-3, 2007.

18- GOMEZ-ANSON B., MACMANUS D.G., PARKER G.J.M., DAVIE C.A., BARKER G.J., MOSELEY I.F., et al.: In vivo $1 \mathrm{H}$-magnetic resonance spectroscopy of the spinal cord in humans. Neuroradiology, 42: 515-7, 2000.

19- CLARK J.F., DOEPKE A., FILOSA J.A., et al.: N-acetylaspartate as a reservoir for glutamate. Med. Hypotheses, 67: 506-12, 2006.

20- MARTIN W.R.: MR Spectroscopy in neurodegenerative disease. Mol. Imaging. Biol., 9: 196-203, 2007.
21- SIMONE I.L., TORTORELLA C., FEDERICO F., LIGUORI M., LUCIVERO V., GIANNINI P., et al.: Axonal damage in multiple sclerosis plaques: A combined magnetic resonance imaging and $1 \mathrm{H}$-magnetic resonance spectroscopy study. J. Neurol. Sci., 182: 143-50, 2001.

22- BLAMIRE A.M., CADER S., LEE M., PALACE J. and MATTHEWS P.M.: Axonal damage in the spinal cord of multiple sclerosis patients detected by magnetic resonance spectroscopy. Magn. Reson. Med., 58: 880-5, 2007.

23- KENDI A., TAN F., KENDI M., YILMAZ S., HUVAJ S. and TELLIOGLU S.: MR Spectroscopy of cervical spinal cord in patients with multiple sclerosis. Neuroradiology, 46: 764-9, 2004.

24- WYSS P.O., HUBER E., CURT A., KOLLIAS S., FREUND P. and HENNING A.: MR Spectroscopy of the cervical spinal cord in chronic spinal cord injury. Radiology, 291 (1). https://doi.org/10.1148/radiol.2018181037, 2019.

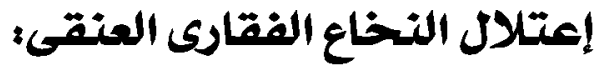

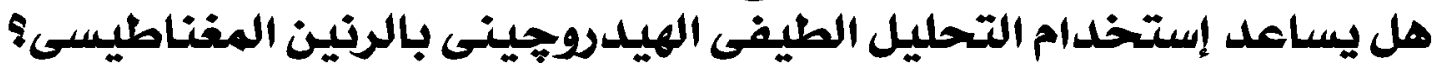

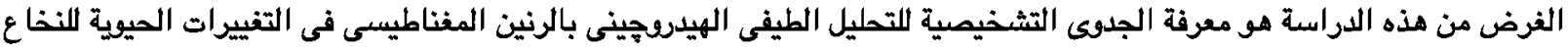 \\ الشوكى العنقى المرضى الذين يعانون من إعتلال النخاع الفقارى العنقى.

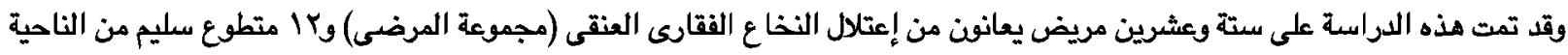

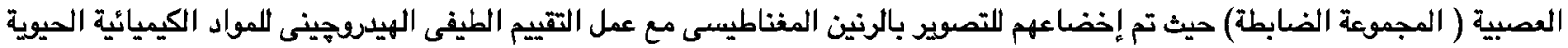

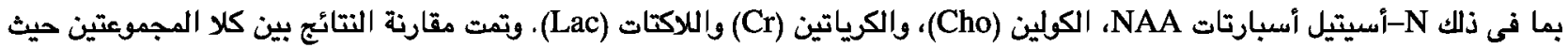

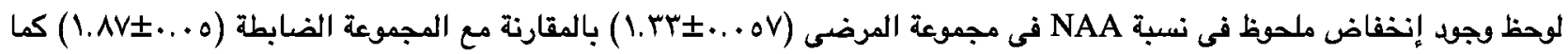

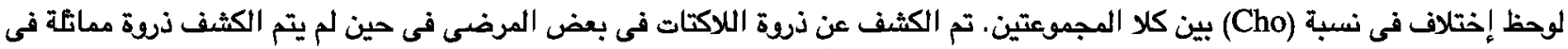 \\ أى من المجموعة الضعابطة، بينما كان الفرق فى نسبة NAA ضئيلاً بين المرضى الذين يعانون من ذروة اللاكتات وهؤلاء بدون تلك الذروة. \\ وخلصت الدراسة إلى أن التحليل الطيفى الهيدرويجينى بإستخدام الرنين المفناطيسى هو تقنية مفيدة وتساعد فى تقييم تغييرات العبل \\ الشوكى فى حالات إعتلال النخاع الفقارى العنقى.
}

